\title{
MEASURING OCCUPATIONAL HEALTH AND SAFETY RISKS IN TOURISM COMPANIES
}

\author{
Chief Assist. Prof. Dr. Preslav DIMITROV, South-West University "Neofit Rilski", \\ Faculty of Economics, Department of Tourism, Blagoevgrad, Bulgaria, e-mail: \\ preslav.dimitrov@mail.bg
}

\begin{abstract}
The present paper focuses on a particular methodology for measuring the occupational health and safety risks in tourism companies by numerical risk coefficients. The methodology is based on the achievements of several US and international research and innovation development programs, such as: "SSP", "ISSP", "F/A-18" and "AFMC". Under this methodology, the occupational health and safety risks are regarded as a function of three variable factors: the likelihood of occurrence of a negative, risk event; the consequences from the realization of this very same risk event and the immediacy of occurrence of the risk event in respect of time. The values of each of these three variables are being measured by the help of score card estimation tables and are being presented as per a zero-referent scale of 1 to 10 or of 1 to 100 . Thus a final estimation of the value of a certain occupational health and safety risk can be achieved. The advantages and the opportunities for improving of this methodology on an enterprise level are reviewed as well. The main advantage which is pointed out is that the methodology could by used even by inexperienced tourism company which has small or small or no past record of health and safety risk measurement.

In the addition to the risk measurement and quantification methodology, a set of criteria for acceptance of the occupational health and safety risks are also presented. This includes: the usage of risk matrixes, the " $\mathrm{f}-\mathrm{N}$ " curves and the "ALARP" principle.
\end{abstract}

Key words: risk measurement and quantification; risk components, numeric risk coefficients 


\section{INTRODUCTION}

The problem of measuring the occupational health and safety risks in tourism companies is a part of the broader problem of measuring the risk at business process level within the organizations. All business processes produce certain risks, which are usually regarded by managers in terms of technical performance, cost, and schedule. In a more holistic approach, the risks within the organization are also regarded as "business risks". And according to a survey conducted by "Arthur Anderson" and "The Economist" and cited by Turner and Hunsucker (Turner, Hunsucker, 1999), "business risk" is defined as, "the threat that an event or action will adversely affect the organizations ability to achieve its business objectives and execute its strategies effectively" ("The Economist", 1996).

The occupational health and safety risks, and especially those within the tourism companies can, also be referred as business risks as they do come from production business process which are more labour intensive than in most of the other sectors of the economy. The complex nature of the tourism product, which comprises a high percentage of service components, and is being consumed on the place of its production, requires tourism personnel to interact not only with certain natural environment, superstructures, facilities, equipment and machinery, but also with the consumers in the very process of production. The occurrence and eventual realization of occupational health and safety risks can increase the scope and scale of the negative, undesired risk consequences from the employees to the tourism companies' objective and business strategies to the tourists as end consumers of the tourism products.

Having into consideration the concept of the occupational health and safety risks in tourism companies as business risks, one can easily apply many of the existing methodologies for quantifying and measuring the business risks and their components. Most of these methodologies however suffer from one main disadvantage: they present risk either as a standard deviation of a certain indicator across an average value, or present some understanding for the risk components which is not clearly explicit and/or does not include all of these very same risk components.

The present paper adapts focuses on a particular methodology for measuring the occupational health and safety risks in tourism companies by numerical risk coefficients. The methodology was presented initially by John V. Turner and John L. Hunsucker in an article named "Effective risk management: a global based approach", published in "International Journal of Technology Management" (Vol. 17, No. 4, 1999, pp. 438 - 458). It includes the achievements of several US and international research and innovation development programs, such as:

- "SSP" ("Space Shuttle Program);

- "ISSP" ("International Space Station Program); 
- "F/A-18" (a project of the US Department of Defense); and

- "AFMC" (US Air Force Material Command).

Later on, this methodology was adapted and implemented for the needs of risk management within the innovation process of the Bulgarian travel and tourism companies, mainly from the sub-sector of the hotel industry (Dimitrov, 2003). The process of adaptation and implementation included 19 hotels across the country which had accepted the proposed methodology for risk measurement and risk management in their innovation process. Specially designed software for online measurement and reporting of the risks was used as well. This adaptation and implementation can be easily transferred to field of occupational health and safety economics as it is explained further on.

A similar methodology was also presented in 2003 by Dimitar Dimitrov and Erdoan Hadzhiev for the need of the risks analysis on the working place and in the labour processes in the transport sector. Dimitrov and Hadziev's methodology differs from Turner and Hunsucker's concept only in the names of the main variables comprising the risk function and in the scaling of these variables which will be explained further on. They also propose a ready to use questionnaire for the purposes of the transport sector in Bulgaria instead of developing of an Integrated Risk Consequences Scorecard.

\section{EXPLAINING THE ADAPTED METHODOLOGY}

The essence of the Turners and Hunsucker's methodology lies on the understanding of Brooks (1994), Stone (1996), and Brinkley (1996) that the risk magnitude can be expressed as a function of a three variables: likelihood, consequence and imminence (Turner, Hunsucker, 1999, p. 441):

$$
R_{(m)}=L_{(m)} \cdot C_{(m)} \cdot I_{(m)},
$$

where:

$R_{(m)}$ is the risk magnitude for risk event, risk action or risk scenario "m";

$L_{(m)}$ - the likelihood (the probability) of occurrence of the risk event, risk action or risk scenario " $m$ ";

$C_{(m)}$ - the integrated risk consequence score for the risk event, risk action or risk scenario " $m$ ";

$I_{(m)}$ - the imminence score (the evaluation of the absence of time for reaction) for the risk event, risk action or risk scenario "m".

Each of the three variables within the risk magnitude equation (1) can be calculated and expressed in terms of numeric coefficients. The values of each of these three variables are being measured by the help of score card estimation 
tables and are being presented as per a zero-referent scale of 1 to 10 or of 1 to 100. Thus a final estimation of the value of a certain occupational health and safety risk can be achieved.

2.1. Determining and evaluating the likelihood of occurrence $L(m)$ of the risk event, risk action or risk scenario " $\mathrm{m}$ "

Quite often managers, and not only in the tourism industry, tend to give directly a certain numeric value for the variable, for the indicator $L(m)$ - the likelihood of occurrence of the risk event, risk action or risk scenario " $m$ ", based only on their intuitive perception. The reliability of such an approach is hard to be proved. Therefore, it is quite useful, in this case, a quantity approach to be applied for determining the numeric value (the estimation) of the variable $L(m)$, even if there is a lack of a reliable information form the past. The F/A-18 program uses exactly such an approach (Hayan, 1996). The F/A-18 likelihood evaluation system a numeric coefficient of 1 to 5 is being assigned to each risk event, action or scenario.

\section{Table 1 -The F/A-18 Program Risk Likelihood Evaluation Method}

\begin{tabular}{|c|l|}
\hline $\begin{array}{c}\text { Likelihood } \\
\text { (probability) numeric } \\
\text { coefficient } \\
\text { (whole number) }\end{array}$ & \multicolumn{1}{c|}{ Description } \\
\hline 1 & $\begin{array}{l}\text { The current work process is sufficient to prevent this type of } \\
\text { risk event, action or scenario from occurring }\end{array}$ \\
\hline 2 & $\begin{array}{l}\text { The current work process is usually sufficient to prevent this } \\
\text { type of risk event, action or scenario from occurring }\end{array}$ \\
\hline 3 & $\begin{array}{l}\text { The current work process may prevent the risk event, action or } \\
\text { scenario but additional actions will be required }\end{array}$ \\
\hline 4 & $\begin{array}{l}\text { The current work process cannot prevent this type of risk } \\
\text { event, action or scenario but a different approach or process } \\
\text { might }\end{array}$ \\
\hline 5 & $\begin{array}{l}\text { The current work process cannot prevent this type of risk } \\
\text { event, action or scenario, no alternative approaches or } \\
\text { process are available }\end{array}$ \\
\hline
\end{tabular}

There could be also a more direct approach to qualitatively assessing the likelihood of occurrence. In order to enable the risk evaluators within the tourism companies to effectively evaluate risks the proposed scale should also contain direct verbal description to each range of used probabilities (Table 2). 
Table 2 - A modified example scale for evaluating likelihood of occurrence $L(m)$

\begin{tabular}{|c|c|}
\hline $\begin{array}{c}\text { Likelihood } \\
\text { (probability) } \\
\text { numeric coefficient } \\
\text { (whole number) }\end{array}$ & Description \\
\hline 5 & $\begin{array}{l}\text { High probability }(\mathrm{P} \geq 0.1) \\
\text { - The risk event, action or scenario may be expected to } \\
\text { occur once in one year of operation or } 60-100 \text { production } \\
\text { cycles (meal orders, room accommodations and etc.) } \\
\text { - The risk event, action or scenario may be expected to } \\
\text { occur once time in the work process/program/project } \\
\text { lifetime }\end{array}$ \\
\hline 4 & $\begin{array}{l}\text { Moderate probability }(0.01 \leq \mathrm{P}<0.1) \\
\text { - The risk event, action or scenario may be expected to } \\
\text { occur once in } 5 \text { years operation or } 300-500 \text { production } \\
\text { cycles (meal orders, room accommodations and etc.) } \\
\text { - The risk event, action or scenario may be expected to } \\
\text { occur once, and could occur more than once in the work } \\
\text { process/program/project lifetime }\end{array}$ \\
\hline 3 & $\begin{array}{l}\text { Unlike probability }(0.001 \leq \mathrm{P}<0.01) \\
\text { - The risk event, action or scenario may be expected to } \\
\text { occur once in } 10 \text { years operation or } 600-1000 \text { production } \\
\text { cycles (meal orders, room accommodations and etc.) } \\
\text { The risk event, action or scenario could occur once in the } \\
\text { work process/program/project lifetime, but multiple } \\
\text { occurrences are extremely unlikely }\end{array}$ \\
\hline 2 & $\begin{array}{l}\text { Remote probability }(0.000001 \leq \mathrm{P}<0.001) \\
\text { - The risk event, action or scenario may be expected to } \\
\text { occur once in } 10 \text { years operation, or more than } 1000 \\
\text { production cycles (meal orders, room accommodations } \\
\text { and etc.) } \\
\text { - The occurrence of the risk event, action or scenario during } \\
\text { the work process/program/project lifetime is extremely } \\
\text { unlikely } \\
\text { - Normally outside the operation envelope, limited hardware } \\
\text { and operational safeguard exist to prevent completion to } \\
\text { failure }\end{array}$ \\
\hline 1 & $\begin{array}{l}\text { Improbable probability }(\mathrm{P}<0.000001) \\
\text { - Occurrence of the risk event, action or scenario is } \\
\text { theoretically possible but such an occurrence is far outside } \\
\text { the operation envelope and robust hardware or } \\
\text { operational safeguard exist to prevent completion to failure }\end{array}$ \\
\hline
\end{tabular}


2.2. Determining and evaluating the imminence $I(\mathrm{~m})$ of occurrence of the risk event, risk action or risk scenario " $\mathrm{m}$ "

The ISSP includes a special attention on the measurement and the evaluation of the imminence $\mathrm{I}(\mathrm{m})$ of occurrence of the risk event, risk action or risk scenario " $m$ ". This variable, this indicator is extremely important in determining which occupational health and safety risks should receive primary attention from the management of the tourism companies (especially in cases of equal probabilities and consequences).

In this regard, the ISSP method supposes a determining of numeric imminence coefficients based on the usage of a function which reflects the sensibility of the tourism companies' managers to this factor. Table 3 provides a visual example of such an imminence function. 
Figure 1 - Developing of an Integrated Risk Consequence Score Card (Source: Turner, J. V. and Hunsucker, J. L., 1999:450)
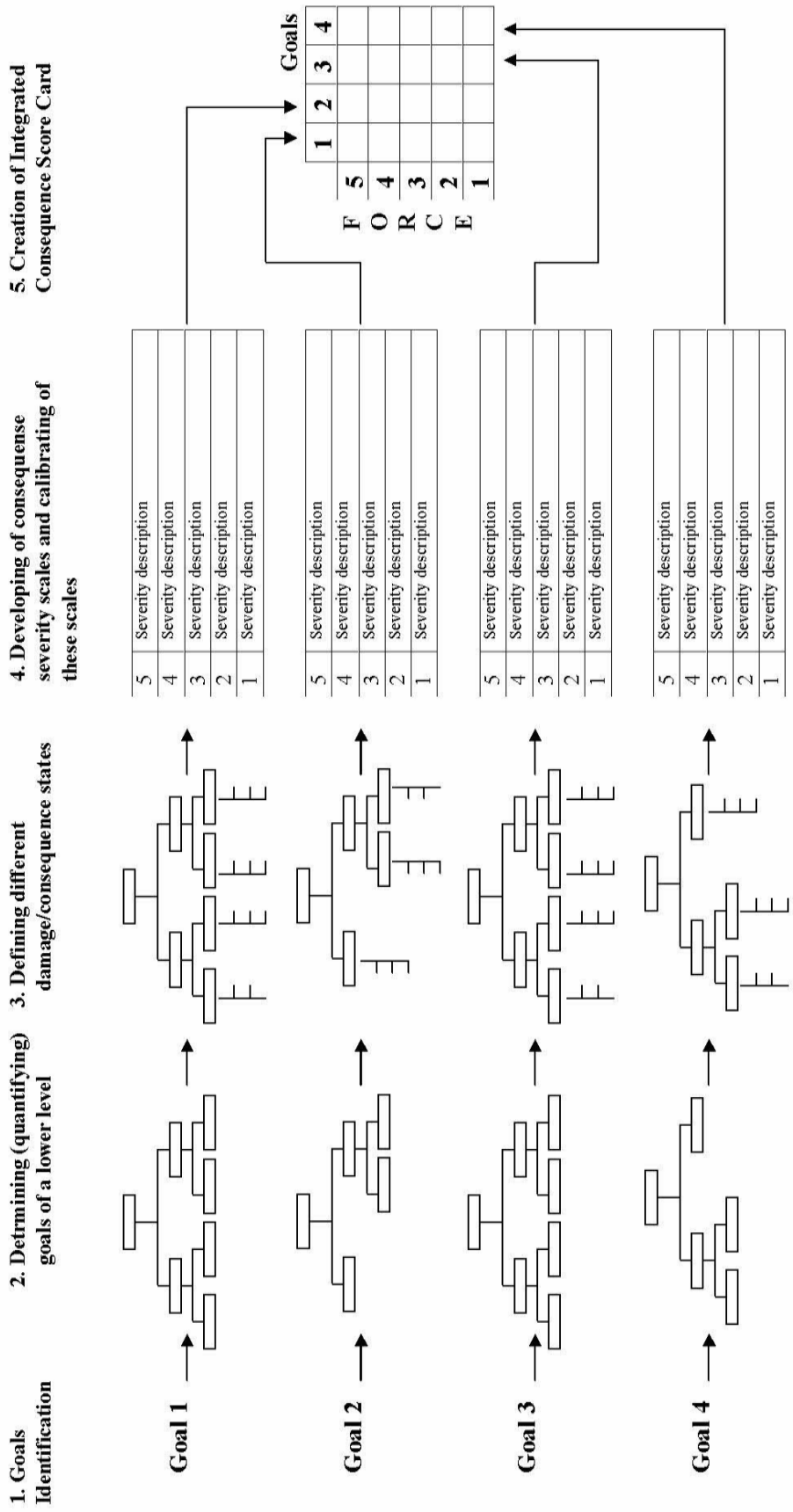
Table 3 - Example scale for determining numeric coefficient of imminence

\begin{tabular}{|c|l|}
\hline $\begin{array}{c}\text { Numeric Coefficient of } \\
\text { Imminence } \mathrm{I}(\mathrm{m})\end{array}$ & \multicolumn{1}{c|}{ Description } \\
\hline 10 & Insufficient time for risk reduction action remains \\
\hline 7 & Little time for risk reduction action remains \\
\hline 3 & Moderate time for risk reduction action remains \\
\hline 1 & Adequate time for risk reduction action remains \\
\hline
\end{tabular}

Similar to the case of determining and evaluating the likelihood of occurrence of the risk event, action or scenario " $m$ ", the numeric coefficient of imminence is being assigned by choosing the most appropriate and adequate to it description.

The descriptions may and should be adapted to the nature and content of the business processes within the travel and tourism companies. They, however, should comply with the common requirement to reflect gradations in the time remaining for action.

2.3. Determining and evaluating the consequences $\mathrm{C}(\mathrm{m})$ from the occurrence of the risk event, risk action or risk scenario " $\mathrm{m}$ "

It is recommended that risk consequences be assessed in such a way, which allows their impact to be accurately and fully determined to all the goals within the tourism organization regardless of their origin. The main purpose here is a risk consequence framework to be established which identifies the impact to top organization of a risk event, action or scenario arising in any of the tourism organization activities or processes. The risk scenarios may potentially include one or more type of risks. The goal of the risk consequences assessment framework is to capture the criteria and priorities used by the top management for every day decision making. This framework should be applied to all organizational decision making within the tourism companies. Without it the comparison of the different in type risk would be problematic (Figure 1).

\section{CRITERIA FOR ACCEPTANCE OF THE OCCUPATIONAL HEALTH AND SAFETY RISKS}

After the calculations for each of the risk components, for each of the risk variables are being achieved, different criteria for acceptance of the occupational health and safety risks can be applied. This includes:

- the usage of risk matrixes;

- the "f-N" curves; and

- the "ALARP" principle

Risk Matrixes. The arrangement of health and safety accident probability and corresponding consequence in a matrix (see Figure 2) may be a suitable 
expression of risk in cases where many accidental events are involved or where single value calculation is difficult (NORSOK Standard, Z-013, 1998). The matrix is separated into three regions as follows:

\section{Figure 2 - Risk matrix}

Increased probability

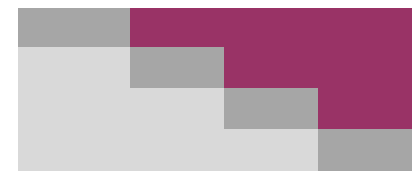

Increasing consequence

$$
\Rightarrow
$$

Unacceptable risk

Evaluate further attention

Acceptable risk

- Unacceptable risk

- Acceptable risk

- A region between acceptable and unacceptable risk, where evaluations have to be carried out in order to determine whether further risk reduction is required or whether more detailed studies should be done first of all.

The limit of acceptability is set by defining the regions in the matrix which represent unacceptable and acceptable risk. The risk matrix may be used for qualitative as well as quantitative studies. If probability is classified in broad categories such as "rare" and "frequent" and consequences in "small", "medium" and "catastrophic", the results from a qualitative study may be shown in the risk matrix. The definition of the categories is particularly important in case of qualitative use.

The categories and the boxes in the risk matrix may be replaced by continues variables, implying a full quantification (Figure 3 ).

\section{Figure 3 - Risk matrix like presentation with continuous variables (Source:} NORSOK Standard, Z-013, 1998)

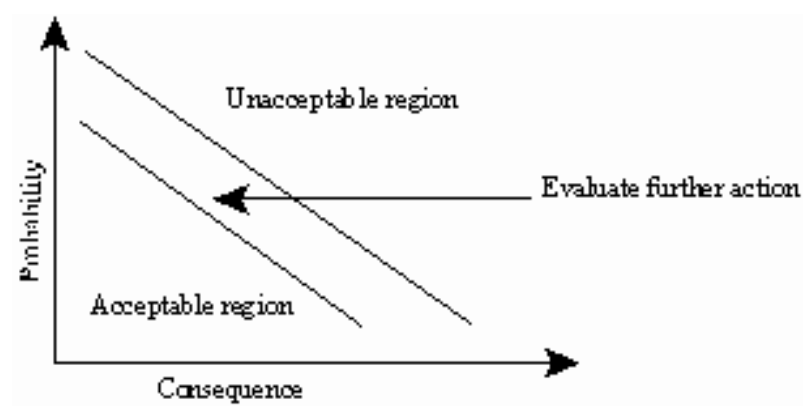


$f-N$ Curves. The $f-N$ curve $(f=$ frequency, $N=$ number, i.e. measurement of consequence) expresses the acceptable risk level according to a curve where the frequency is dependent on the extent of consequences (such as number of

Figure 4 - f-N curve (Source: NORSOK Standard, Z-013, 1998)

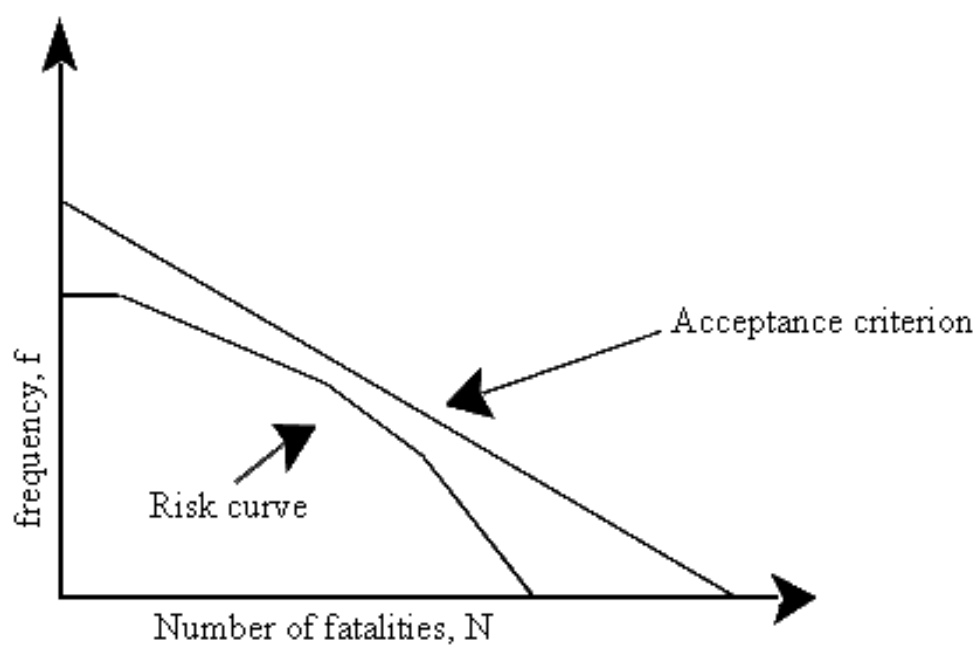

Figure 5 - The ALARP-principle (Source: NORSOK Standard, Z-013, 1998)

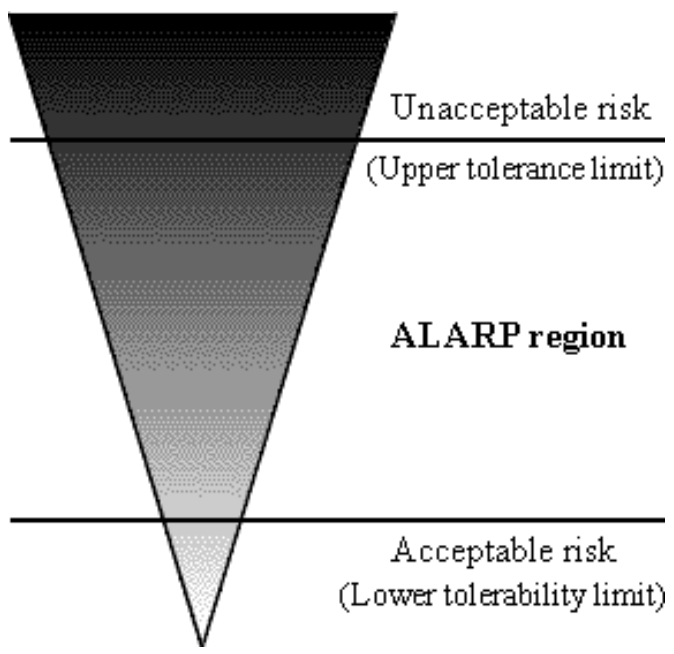

fatalities per accident). The acceptance limit may be adjusted according to the resource which is exposed. The $\mathrm{f}-\mathrm{N}$ curve used as an acceptance limit may reflect aversion to major accidents (with multiple fatalities), if the curvature is different from an "iso-risk" line (along which the product of $f$ and $\mathrm{N}$ is constant). 
The calculation of values for the $\mathrm{f}-\mathrm{N}$ curve is cumulative, i.e. a particular frequency relates to "N or more" fatalities. Figure A3 presents an illustration.

Figure 6 - Risk Measurement and Calculation Online Interface designed for Bulgarian tourism companies (Dimitrov, 2003)

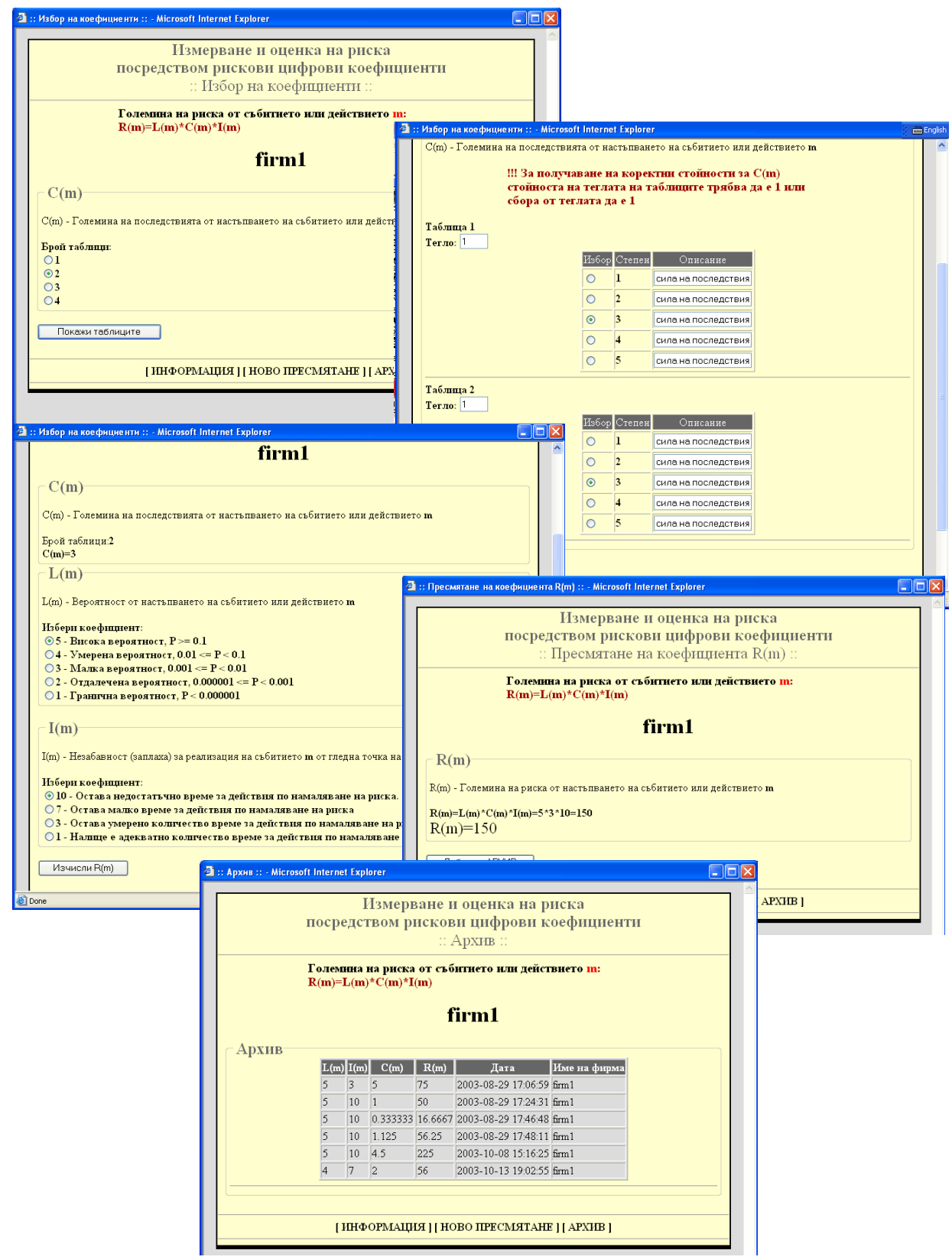


The $\mathrm{f}-\mathrm{N}$ curve may be used in relation to risk acceptance for personnel, environment and assets.

"ALARP" principle. The ALARP ("As Low As Reasonably Practicable", see Figure 5) principle is sometimes in the industry used as the only acceptance principle and sometimes in addition to other risk acceptance criteria.

The use of the ALARP principle may be interpreted as satisfying a requirement to keep the risk level "as low as possible", provided that the ALARP evaluations are extensively documented.

The risk level shall be reduced as far as possible in the interval between acceptable and unacceptable risk. The common way to determine what is possible is to use cost-benefit evaluations as basis for decision on whether to implement certain risk reducing measures.

The upper tolerability limit (see Figure 5) is almost always defined, whereas the lower tolerability limit may sometimes be left undefined. This will not prohibit effective use of the approach, as it implies that ALARP evaluations of risk reducing measures will always be required.

The ALARP principle used for risk acceptance is applicable to risk to personnel, environment and assets.

\section{ADVANTAGES, DISADVANTAGES AND CONCLUSIONS}

The main advantage which is pointed out is that the methodology could by used even by inexperienced tourism company which has small record of health and safety risk measurement. This advantage was applied by Dimitrov and Hadzhiev in the transport sector in their variation of the risk assessment and measurement methodology (Dimitrov, Hadzhiev, 2003). Another industrial sector which implements in Bulgaria a version of the Turner and Hunsucker's methodology is the mining sector in the face of the mining company "Union Minier Pirdop Copper" AD which has transferred it to its risk assessment manuals.

The second advantage is that the methodology could be used through a specially designed web interface for online risk monitoring, evaluation and management by the headquarters of tourism companies which have subsidiaries and facilities in remote destination (see Figure 6). This can be achieved without a substantial financial burden especially via the existing corporate intranet and extranet information systems. Such an online approach to the application of risk measurement methodology is recommended in most of the guidelines (such as: The University of Queensland, Occupational Health \& Safety Unit, 2009) to some of the existing national standards for risk management (AS/NZS 4360:1999; NORSOK STANDARD, Z-013:1998, Australian Risk Management Advisory Standard 2000). 
The main disadvantage and shortcoming of the adapted Turner and Hunsucker's methodology for measuring occupational health and safety risks in tourism companies is that it relies heavily on subjective personnel or expert judgments. This shortcoming could be overcome to some extent by multiple repeated measurements and/or by using not a single but a group of evaluators.

\section{REFERENCES}

Andrews, H., (2005), "Health and safety as a strategic issue", Managing Business Risk, $2^{\text {nd }}$ Edition, Jonathan Reuvid (edit.), Kogan Page, London and Sterling, VA: 187-191

\section{Australian Standard AS/NZS 4360:1999 - Risk management}

Brinkley, R., Stone, D., (1996), "International Space Station Program Directive Program Risk Management Emphasis System", ISS-PD-011, NASA, Johnson Space Center, Houston, Texas, USA

Brooks, W. M., (1994), "Project Risk Management (a presentation given at Johnson Space Center, May 9-11, 1994)", Johnson Space Center, Houston, Texas, USA

Cushway, B., (2005), "Creating a safe working environment", Managing Business Risk, $2^{\text {nd }}$ Edition, Jonathan Reuvid (edit.), Kogan Page, London and Sterling, VA: 179-185

Dimitrov, D., Hadzhiev, E., (2003) "Analysis of Place of Work and Labour Process Risk in Transport", Scientific Journal "Mechanics, Transport, Communication", Issue: 1/2003, Article No. 0007, http://www.mtc-aj.com

Dimitrov, P., (2003), "Risk Management in Tourism Innovations", Heron Press, Sofia, Bulgaria

Dimitrov, P., (2006), "Tourism Innovations", "Neofit Rilski" University Press, Blagoevgrad, Bulgaria

Hayan, J. A., (1996), F/A-18 "Risk management plan", Report MDC 960074, McDonnel Douglas Aerospace, St. Luis, USA

Lyons, S., (2005), "Managing your most valuable asset, protecting your most vulnerable resource", Managing Business Risk, $2^{\text {nd }}$ Edition, Jonathan Reuvid (edit.), Kogan Page, London and Sterling, VA: 192-197

NORSOK STANDARD, "Risk and Emergency Preparedness Analysis", Z-013, Rev.1, March 1998, Annexe A "Risk Acceptance Criteria", Norwegian Technology Standards Institution, Oslo, Norway 
Risk Management Advisory Standard 2000: Department of Employment, Training and Industrial Relations - Workplace Health and Safety, http://www.detir.qld.gov.au/hs/hs.htm

The Economist, (1996), A Game of Risk - The Economist Survey, Corporate Risk Management, $10^{\text {th }}$ February, 1996;

The University of Queensland, Occupational Health \& Safety Unit, (2009), Occupational Health \& Safety Risk Assessment and Management Guideline, http://www.uq.edu.au/ohs/pdfs/ohsriskmgt.pdf

Turner, J. V. and Hunsucker, J. L. (1999), "Effective risk management, a goalbased approach", International Journal of Technology Management, Vol. 17, No.4: 438-458 